\title{
Design of solar supply system for water quality improvement equipment
}

\section{used in the pond}

\author{
Pang Chuang-chuang ${ }^{1, a}$, Wang Yong-ding ${ }^{1, b}$ \\ ${ }^{1}$ College of Engineering, Shanghai Ocean University, Shanghai ,China; \\ achchpang@163.com, bsmmsh@sh163.net
}

\begin{abstract}
Key words: Solar power supply; Water quality improvement equipment; Solar array; Controller Abstract: in view of the design of the power supply system of the pond water quality improvement, the system scheme of the power supply of the equipment is put forward.The basic principle of solar power supply system is analyzed;The configuration principle, main components and technical performance of the power supply system of solar power supply system are studied;In the specific environment and parameters, the factors that need to be considered in the power distribution of the water quality improvement machine are analyzed.A set of feasible scheme is proposed for the application of solar energy in the pond water quality improvement.
\end{abstract}

\section{Introduction}

With the artificial breeding technology, and combined with mechanical aeration technology is widely used in feed, aquaculture has become the main production mode of aquaculture in china.Because most of the pond culture adopt the traditional breeding method, the feed, fertilizer and so on in the process of breeding is very small, and a large amount of organic matter deposit to the bottom of the pond or discharged into the external environment. Water quality improvement equipment is mainly used in power supply, power supply equipment is complex, heavy workload, high cost, in some remote mountainous areas or power is not easy to use in the area difficult to use.Most of China has abundant solar energy resources, the full use of solar energy can not only save energy but also reduce pollution. Therefore, it is significant to develop a kind of solar power supply system which can improve the water quality.

At present, the application of solar energy in aquaculture is rare in recent years, some researchers applied the solar energy detection system of aquaculture, there are people making solar feeding machine.The implementation of the solar energy application in the water quality improvement is still very few examples.Solar water quality improvement by the power source, the bottom of the sewage pumping, floating body and other devices.Power source device is mainly composed of solar cells, controller and other parts, mainly for water quality improvement machine to provide power source and control system.The sewage pumping unit is composed of a pumping pipe and a vortex pump. The lower end of the pumping pipe is close to the bottom surface of the pool, and the upper end is near the water surface. The floating body device comprises a water body, a motor, a motor, a rope and a supporting rod, and a rope is arranged on the shore of the pond in accordance with the water and route for the preparation work. When the light intensity of the light reaches the starting intensity, the device starts to run.Through the controller, the electric energy generated by the solar cell group is supplied to the turbine motor, and the bottom water of the pond is pumped to the water surface through a pumping pipe. The other part is conveyed to the DC motor 
of the floating body, and the traction wheel is driven by the friction force to drive the water quality improving machine along the rope.The solar power supply system designed in this paper is designed by the solar cell group to convert solar energy into electrical energy through the controller directly to the load, without the need to design and install the battery, the structure is simple, the cost is low, easy to operate.

\section{Principle and composition of solar power supply system}

Solar power supply system includes solar cell, controller, load and system structure as shown in Figure 1.

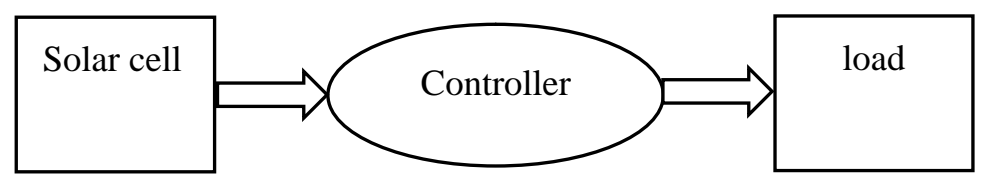

Fig.1 The solar power system structure diagram

Solar cell is the core part of the solar power supply system, which is composed of a series of parallel connected components.Solar cells accept the solar energy, and through the controller to achieve the load power supply, solar cells and the controller constitutes a solar power system. The controller is composed of a light control circuit and start / stop control circuit is connected with the solar battery and the load, the hub. The power supply of the solar cell is directly supplied by the main motor, and the rotary motor is supplied by the power supply.

\section{Configuration and design of solar power supply system}

To design a safe, reliable and efficient solar power supply system, from the following two factors to consider.The first is the design and working condition of the water quality improvement machine itself, including the parameters of solar cell, the design of the controller, the working condition of the equipment and so on. Another important factor is the natural conditions of the region, such as latitude and longitude, sun light, climate, etc..

According to the characteristics of the standard pond culture, the main technical parameters of the solar water quality improvement equipment are shown in Tab.1.In order to meet the design requirements, the main motor selection of the rated voltage $24 \mathrm{~V}$, rated power $200 \mathrm{~W}$, speed $250 \mathrm{r} / \mathrm{min}$; rotary motor rated power $10 \mathrm{~W}$, rated voltage $24 \mathrm{~V}$. Working hours are 6 hours per day. The configuration and design of solar power supply system is closely related to the geographical position, the situation of the solar radiation, the terrain and the weather conditions. In this paper, the design parameters of the main breeding season May to September in Shanghai are selected, and the solar cell module of $110 \mathrm{~W}$ and $12 \mathrm{~V}$ is selected as the power source for the system. 
Tab.1 Main technical parameters of the prototype

\begin{tabular}{cc}
\hline Project & parameter \\
\hline Water lifting capacity/ $\left(\mathrm{m}^{3} / \mathrm{h}\right)$ & $\geqslant 120$ \\
\hline Suitable for working water depth range $/ \mathrm{m}$ & $1 \sim 2$ \\
\hline Load noise $/ \mathrm{dB}$ & $\leqq 78$ \\
\hline Advance speed of sediment lifting device/ $(\mathrm{m} / \mathrm{s})$ & 0.4 \\
\hline Moving speed of the surface moving device $/(\mathrm{m} / \mathrm{s})$ & 0.02 \\
\hline working radius $/ \mathrm{m}$ & $10 \sim 20$ \\
\hline Main motor voltage/ & 24 \\
\hline Main motor power/w & 200 \\
\hline Rotary motor voltage/ $/ \mathrm{w}$ & 24 \\
\hline Rotary motor power $/ \mathrm{w}$ & 10 \\
\hline
\end{tabular}

\section{main motor parameters calculation}

According to the structure and equipment working requirement of standard culture pond, this paper designs the $120 \mathrm{~m}^{3} / \mathrm{h}$ of the water body, and the $0.3 \mathrm{~m}(\mathrm{~W})$. As shown in Eq. 1:

$$
p_{e}=\frac{\rho g Q H}{\eta}
$$

In the type: $\rho$ is the density of water is $1 * 10^{3} \mathrm{~kg} / \mathrm{m}^{3} ; \mathrm{g}$ is the acceleration of gravity, take $9.8 \mathrm{~m} / \mathrm{s}^{2}$.; Q is the amount of water, the value of $120 \mathrm{~m}^{3} / \mathrm{h} ; \mathrm{H}$ is pumping height, take $0.3 \mathrm{~m} ; \eta$ is the total power factor value of 0.6 .

The power required for the load swing motor is $167 \mathrm{~W}$. According to the specifications of the DC motor, the rated voltage $24 \mathrm{~V}$, rated power $200 \mathrm{~W}$ DC motor as the main motor.

The function of the rotary motor is to rotate through the motor rotating traction belt, relying on the friction to make the whole water quality control equipment along the traction rope movement, design requirements of the surface walking device movement speed is $0.02 \mathrm{~m} / \mathrm{s}$, slowly moving in the water, the speed is small, select the speed $24 \mathrm{~V}$, rated voltage $5 \mathrm{r} / \mathrm{min}$, rated power $10 \mathrm{~W}$ motor can meet the system requirements.

According to the above calculation, the total power of the load P1 is $210 \mathrm{~W}$.

\section{Solar cell array design}

\section{Parameter calculation of solar cell array}

According to the Shanghai city pond breeding season is mainly May to September.The main work of the design of the bottom of the pond is working in this time period, so the design and calculation of the sun light is made according to the time period. According to the radiation parameters of the major cities in China, the radiation value of Shanghai is 1260, which is converted into the average daily radiation under the standard illumination H.As shown in Eq. 2:

$$
H=2.77 \times 10^{-4} \times H_{T}
$$

So $\mathrm{H}$ is $3.545 \mathrm{~h}$, and the average value of September to May is 1.28 times that of the whole year, so the average daily radiation time from September to May is $4.5 \mathrm{~h}$. 
According to the load power, the power of the solar cell array is calculated by P.As shown in Eq. 3:

$$
P=\frac{p_{1} t}{H \eta_{2}}
$$

In the type:P1 is the total load power,is the main power of main motor and rotary motor power, is $210 \mathrm{~W}$; $\mathrm{t}$ is the load average daily working time, is $6 \mathrm{~h} ; \mathrm{H}$ is the average daily radiation time ,is $4.5 \mathrm{H}$; the 2 is the ETA charge loss, is 0.7 . After calculation, the power of the solar cell array is 400W.

According to the design of solar cell module in this paper, the solar cell module is $12 \mathrm{~V} / 110 \mathrm{~W}$, which can be selected from 4 sets of same size of two sets of solar cell components in parallel, and the two groups are connected in series. Its voltage is $24 \mathrm{~V}$, the optimal working current is $9.1 \mathrm{~A}$, the rated power is $440 \mathrm{~W}$. See Table 2 .

Tab.2 Solar cell array design

\begin{tabular}{cc}
\hline Project & numerical value \\
\hline Design month & $5 \cdot 9$ \\
\hline Peak sunshine hours/h & 4.5 \\
\hline Single block solar cell module power/W & 110 \\
\hline Single block solar cell module voltage/V & 12 \\
\hline system voltage/V & 24 \\
\hline Number of components in series & 2 \\
\hline Number of components in parallel & 2 \\
\hline Number of solar cells required & 4 \\
\hline
\end{tabular}

\section{parameter calibration}

The total power of the load P1 is $210 \mathrm{~W}$, the load of the average daily working time is 6 hours, the load per day is W.As shown in Eq. 4:

$$
W=P_{1} \times t
$$

Calculate the load per day to work the required quantity is $1.26 \mathrm{~kW} \cdot \mathrm{h}$.

Solar cells produce power QP a day.As shown in Eq. 5:

$Q_{P}=I \times H \times K \times C_{Z} \times U \times 4$

In the type: $\mathrm{I}$ is the best working current of the solar cell components, is $9.1 \mathrm{~A}$; $\mathrm{K}$ is slant correction parameters, take 0.99 ; $\mathrm{C}$ is correct parameters, mainly system loss, take 0.8 ; $\mathrm{U}$ are rated voltage, is $12 \mathrm{v}$. After a $\mathrm{QP}=1.56 \mathrm{~kW} \cdot \mathrm{h}$ is calculated.QP is greater than $\mathrm{W}$, so the energy provided by solar cell phalanx is able to meet the energy needed to power system operation.

\section{The design of the electric controller}

\section{Charge controller design}

In solar water quality improvement device, the controller is connected with the solar cell, the load of the hub, control the coordination of the work. Controller selects the single chip microcomputer as the core control unit. The controller for improving the water quality of equipment 
shall be controlled and has the function of remote control. The discharge control circuit is composed of MOS tube and peripheral resistance. According to the test results of the solar cell voltage, through the core control unit MCU control of the circuit and disconnect the power supply to the load. At the same time, the single chip microcomputer is used as the load control processor, to realize the control and detection of the load.

Controller is an important part of power supply system, and it is also the core of the whole water quality improvement equipment system. The following discussion of the controller should have the function and should pay attention to the problem:

1)Light control system of the solar battery power conversion main motor is supplied directly to a road, a road through the regulated power supply of rotary motor. When the light intensity is higher than the start threshold threshold, optical control circuit output contact is closed, solar panels for power supply system; the light intensity is lower than the stop threshold, light control circuit output contact disconnect, solar panels to stop power supply system.

2)Load and floating boat running control.Through the power supply system, the electric energy is supplied to the turbine motor of the sewage pumping unit, and the bottom water is pumped to the water surface, and the anti - acting force of the water is used to drive the sewage pumping unit to circle the floating body; The other part is supplied to the DC motor mounted on the floating body, and the traction belt wheel is driven by the friction control circuit.

3)In the application, we can design the running route of the water surface walking device according to the actual situation, and add the corresponding control circuit in the controller. For example, the surface of the device in the role of the rotary motor to do the reciprocating movement along the traction rope, can design the corresponding start / stop control loop to meet the requirements.

4)Controller with remote control function, the staff can directly control the device's start and stop.

5)Control system should have a certain protective performance, to prevent the short circuit and other causes of equipment damage.

6)Controller performance. Because the water quality improvement machine works in the remote areas, the maintenance is very inconvenient. Therefore, the selection of the controller must be running safe and reliable, and is not prone to failure. In addition, the controller has a high efficiency, work stability is also very important.

\section{Conclusions}

This paper mainly studies and designs the solar power supply system of the solar cell, such as the configuration of the solar cell array, the controller, and so on.Through the theory and the design of the specific parameters, a set of feasible system scheme is proposed for the application of solar energy in water quality improvement. At present, the price of solar cell is still very high, which affects the popularization and application of solar energy technology in aquaculture industry. With the development of science and technology, the cost of solar cells is reduced, and the application of solar power supply system in the field of fishery machinery will be more and more extensive. 


\section{Acknowledgements}

This work was financially supported by the Shanghai agriculture science and technology key project(D-8004-14-0249).

\section{References}

[1] Xu Hao, Liu Xingguo, Wu Fan, et al. The main technology and transformation mode of the construction of pond culture equipment. China Fisheries, 2009(8):7-9;

[2] Wang Yongding. The waterwheel type aerator in the solar energy application research. Fisheries Science \& Technology Information, 2006; 33 (5): 222 - 224

[3] You Guodong, Yang Shifeng, Li Jisheng,et al. Solar powered water aeration system and operation effect. Transactions of the Chinese Society of Agricultural Engineering, 2012; 28 (13): 191- 198

[5] Yang Jiapeng,Zhang Yongjun,Tang Rong, et al. The design of solar photovoltaic power supply system of the feeding machine.Fishery Modernization 2014(2):28-31

[6] Tian Changfeng, Liu Xingguo, Zhang Yongjun. The development of the pond geology improved machine. Journal of shanghai Ocean University,2013(7):616622

[7] Yan Fangfang,Zhang Shuguang,Suo Xuesong,et al. Design of data acquisition system for agricultural greenhouse solar power supply. ournal of Agricultural Mechanization Research,2013(5):103-106 